Article

\title{
Medical Assistant Mobile Application for Diabetes Control by Simulating a Compartmental Model
}

\author{
Martín Hernández-Ordoñez ${ }^{1, *}$, Marco Aurelio Nuño-Maganda ${ }^{2}$ (D), \\ Carlos Adrián Calles-Arriaga ${ }^{2}$, Abelardo Rodríguez-León ${ }^{3, * \mathbb{D}}$, \\ Guillermo Efren Ovando-Chacon ${ }^{1, *} \mathbb{1}$, Rolando Salazar-Hernández ${ }^{4}$, Omar Montaño-Rivas ${ }^{5}$ \\ and José Margarito Canseco-Cortinas ${ }^{2}$ \\ 1 Department of Metal-Mechanics, México National Technological/I.T. Campus, Veracruz 91860, Mexico \\ 2 Intelligent Systems Department, Polytechnic University of Victoria, Tamaulipas 87138, Mexico; \\ mnunom@upv.edu.mx (M.A.N.-M.); ccallesa@upv.edu.mx (C.A.C.-A.); 1229002@upv.edu.mx (J.M.C.-C.) \\ 3 Department of Systems and Computing, México National Technological/I.T. Campus, \\ Veracruz 91860, Mexico \\ 4 Facultad de Comercio, Administración y Ciencias Sociales, Universidad Autónoma de Tamaulipas, \\ Tamaulipas 87000, Mexico; rsalazar@uat.edu.mx \\ 5 Academy of Information Technologies, Polytechnic University of San Luis Potosí, San Luis 78369, Mexico; \\ omar.montano@upslp.edu.mx \\ * Correspondence: martin.ho@veracruz.tecnm.mx (M.H.-O.); abelardo.rl@veracruz.tecnm.mx (A.R.-L.); \\ guillermo.oc@veracruz.tecnm.mx (G.E.O.-C.)
}

Received: 29 July 2020; Accepted: 25 September 2020; Published: 29 September 2020

check for updates

Featured Application: Mobile application for iterative simulation of a diabetic model.

\begin{abstract}
This paper presents an educational mobile assistant application for type 1 diabetes patients. The proposed application is based on four mathematical models that describe the glucose-insulin-glucagon dynamics using a compartmental model, with additional equations to reproduce aerobic exercise, gastric glucose absorption by the gut, and subcutaneous insulin absorption. The medical assistant was implemented in Java and deployed and validated on several smartphones with Android OS. Multiple daily doses can be simulated to perform intensive insulin therapy. As a result, the proposed application shows the influence of exercise periods, food intakes, and insulin treatments on the glucose concentrations. Four parameter variations are studied, and their corresponding glucose concentration plots are obtained, which show agreement with simulators of the state of the art. The developed application is focused on type- 1 diabetes, but this can be extended to consider type- 2 diabetes by modifying the current mathematical models.
\end{abstract}

Keywords: mathematical models; Iterative simulation; compartmental model; diabetes control; mobile assistant

\section{Introduction}

In recent years, obesity and overweight have become a severe problem for human health. In 2014 more than 1.9 billion adults aged 18 and older were overweight globally, from which over 600 million were obese. The data indicated that $39 \%$ of these adults were overweight and $13 \%$ were obese [1]. Body mass index (BMI) provides the most useful population-level measure of overweight and obesity as it is the same for both sexes and all ages of adults. Patients with higher BMI are at greater risk for having diabetes. In 2014, more than 422 million people had diabetes in the world, with a global prevalence of $8.5 \%$ among adults over 18 years old. Diabetes is a leading cause of blindness, kidney failure, heart attacks, stroke and lower limb amputation. In 2012, an estimated 1.5 million deaths 
were directly caused by diabetes, and another 2.2 million deaths were attributable to high blood glucose [2]. Diabetes was promoted from 21st place in 1990 to the 14th in 2010 in the list of death causes worldwide [3], and recently, to the 6th place in 2016 [4].

In Mexico, about $72.5 \%$ of adults from 18 years and over, $36.3 \%$ of teenagers, and $33.2 \%$ of children were overweight or obese in 2016. Diabetes statistics are not too optimistic; Mexico is in sixth place in countries with more diabetes, just behind China, India, US, Brazil and Russia [5]. Recent statistics show that $9.17 \%$ of adults from 18 years (about 6.4 million people) have diabetes [6]. Type 2 diabetes has become the leading cause of death in Mexico. The disease claims nearly 80,000 lives each year, and forecasters say the health problem is expected to get worse in the decades to come [7].

On the other hand, smartphones have been accessible to more people due to the high worldwide market growth rate. In 2016, around 1.5 billion smartphones were sold worldwide [8]; by the end of 2016, more than 3.2 billion individuals worldwide used the Internet regularly, accounting for nearly $45 \%$ of the world's population; about 2.5 billion people access the web via mobile phone [9], which represents novel opportunities for designing applications running on smartphones, accessible to large population groups. Specifically, healthcare and disease management have benefited with applications such as fitness tracking, drug dose calculators, information apps, tutorials, surveys, diaries, and other tools created to help empower users to put more emphasis on their health care. Some benefits of using smartphones with Internet connectivity consists of the possibility of sharing data with family, friends, classmates, colleges, collaborators but especially with professionals who can guide the user and give feedback regarding treatment to be followed.

This paper is structured as follows. In Section 2, a concise review of the state of the art is given. A description of the models used in the developed application is provided in Section 3. In Section 4, the results and discussion are described. Finally, in Section 5, the conclusion is presented where final recalls are established, and future work is outlined.

\section{State of the Art}

\subsection{PC or Web Simulators for Glucose Concentration Levels}

In recent years, an effort to implement glucose levels simulators has been made. One standard option for implementing simulators are PCs or Laptops. PCs have as their main advantage the inherent high computational power for performing simulations. In addition, there has been a trend to replace PCs with much more compact devices, such as smartphones, but most simulators for glucose concentration are PC-based. Another implementation option consists of Web systems, allowing for a broad range of devices to access such simulation systems. Web-based simulators have an advantage: many platforms can access the simulator compared to a particular PC implementation. Web-based simulators have as main disadvantage the requirement of Internet connectivity, making the simulator difficult to access in places with connectivity problems.

In [10], the AIDA diabetes simulator is presented, and extensive evaluation about this simulator has been reported in [11]. Recently, new types of rapid-acting insulins have been added to the AIDA diabetes simulator [12]. AIDA's mathematical model was created to simulate glucose tolerance; however, its use is not based on daily periods.

In [13], the REACTION project is presented. This project consists of a set of healthcare services oriented to diabetic patients and caregivers through a cloud-based application focusing on management and therapy services. The REACTION project is a management system created for the implementation of logistics related to medical personnel. The dosage management algorithm is based on basic rules, and it is not a pharmacological-dynamic behavioral study of insulin. In other words, it is a mathematical model with experimental parameters.

In [14], GLUCOSIM is proposed as a desktop application designed to do virtual experiments to show the effects of food intake changes and insulin therapy on glucose levels. A more detailed version of this system is reported in [15], where a Web-based solution was included. It is important 
to mention that GLUCOSIM is a tool designed to study, train and analyze the external effects that modify glucose concentration. It uses three mathematical models to consider all the mentioned effects; however, it does not describe periods of exercise or other modeled effects.

In [16], a system is proposed based on the combination of Compartmental Models (CMs) and artificial Neural Networks (NNs). Data from a Type 1 diabetes patient, which contains information about measured blood glucose levels, insulin intake, and food intake description, along with the corresponding time, were used as input to the model. The proposed strategy was not adequately validated. Furthermore, no performance criteria were mentioned to assess the results objectively.

The literature review indicates that early studies of compartmental modelling of glucose/insulin interactions were proposed since the 1980s in [17-19]. On the other hand, recently, different research groups have reported important works related with the implementations of compartmental models to develop glucose level simulators, for example, in [20,21] are presented a glucose forecasting algorithm based on a compartmental composite model of glucose-insulin dynamics. In [22] is developed a dynamic model for type 1 diabetic patient that focuses on blood glucose regulation. A first model for insulin adsorption in infusion sets using a minimal lumped two-compartment modelling approach is reported in [23]. A review of the key role of the UVA/Padova simulator is presented in [24], which has tested the use of new molecules for better glucose control.

\subsection{Mobile Applications for Diabetes Management}

The universe of mobile applications for diabetes care is enormous. A first step consists in determining the utility of apps. One standard classification includes exercise and fitness apps, med adherence, weight management, blood glucose trackers, support, healthcare professional apps, and educational simulators. There is extensive availability of applications related to any of the previously mentioned apps, but few efforts are related to educational simulators for smartphones.

One interesting branch of smartphone applications for health care is the simulators. In this paper, we are specifically interested in creating a smartphone-based simulator of glucose-insulin metabolism. In recent years, there have been advances in creating models that can replicate the behavior of parts (or entire) of human organisms and their corresponding implementation as a computer simulation. A smartphone-based simulation can be useful for patients with recently diagnosed diabetes to help them estimate the insulin doses and food intake, but also for patients at risk of developing diabetes or without diabetes, for contributing to raising awareness of the benefits of changing their food consumption and exercise habits. In [25], a review of several diabetes simulators is presented, but the applications reported in that paper is out of the scope of this work, since there is an interest in providing a realistic simulation of blood glucose levels.

There are several reviews of applications for diabetes management. In [26], a set of critical factors to be considered when designing diabetes management applications are explored. These factors come from patient demographics, technology costs, platform varieties, and ease of use. They also categorize the applications in the following classes: blood glucose logging, nutrition databases, carbohydrate tracking, tracking physical activity and weight, data-sharing and social support, and short messages and reminders. An important point to consider is that the FDA does not approve most applications. In [27], several commercial applications for diabetes management available on the Apple App Store and articles published in relevant databases are reviewed. The reviewed applications support self-management tasks such as physical exercise, insulin dosage or medication, blood glucose testing, and diet. Other support tasks considered include decision support, notification/alert, tagging of input data, and social media integration. Analysis indicates that application usage is associated with improved attitudes favorable to diabetes self-management. Limitations of the applications include lack of personalized feedback; usability issues, particularly the ease of data entry; and integration with patients and electronic health records. In much more detail, in [28], it is concluded that a critical feature strongly recommended by clinical guidelines-namely, personalized education is not assimilated in current diabetes applications. In [29] a critical assessment was reported of several smartphone apps for 
calculating insulin dose. The conclusion was that popular apps offering insulin dose calculations carry a risk of incorrect dose recommendations ranging from those that might lead to suboptimal disease control to those with potentially life-threatening consequences. In [30], an analysis of the benefits of smartphone apps for type 2 diabetes mellitus (T2DM) self-management was presented. It can be concluded that more research with valid study designs and longer follow-up is needed to evaluate the impact of health apps for diabetes care and self-management, specifically for T2DM. In [31], both Heuristic and keystroke level modeling (KLM) are used to measure efficiency for each analyzed mobile diabetes management application for patients with Type-1 Diabetes Mellitus.

With recent advances in connectivity technologies, there are some efforts to build tools based on cloud computing [32] or social network support [33,34]. One disadvantage of these tools is that they always require Internet connectivity at all times, which makes them useless in places with connectivity problems. Some applications are targeted to a particular segment of the population, such as pregnant women; one of these applications is reported in [35,36], where a tool to follow patients with gestational diabetes is described. In [37], an application for insulin dose calculation is reported. The authors establish that this application's innovation consists of the incorporation of exercise and alcohol intake to the calculator in addition to carbohydrates intake. In [38], an application created explicitly for controlling an insulin pump taking as real-time input data from a continuous glucose monitor is reported. A closed-loop control system used to automatically manage insulin infusion to maintain the desire range's glucose level is proposed. To summarize, there is a strong interest from the scientific community in developing applications around the problems associated with diabetes. This article adds to this trend with an emphasis on the exercise model.

\section{Models}

The idea of creating an artificial model for a glucose-insulin system for several purposes has been widely explored. In [39], a minimal glucose-insulin system is proposed; the model starts with the Bergman model [17] and presents modifications to improve, considering the glucose level's description in the subcutaneous layer and a meal disturbance term. The developed application uses four mathematical models related to them, following the different dynamics that they describe:

1. Glucose-Insulin Model: Sorensen in [40] proposed it. This model comprises 19 nonlinear differential equations, which include significant metabolic effects related to glucose regulation. The model was obtained through a compartmental technique, where the pancreas compartment is omitted to consider a type 1 diabetic patient. Recently, this glucose-insulin model was extended to consider exercise periods [41].

2. Subcutaneous Insulin model: Berger and Rodbard [42] obtained it. This model describes the subcutaneous insulin uptake pattern after an insulin injection. The model considers interactions between components after subcutaneous injections such as insulin absorption and elimination in plasma insulin, active insulin, glucose utilization, plasma glucose, and glucose input. The model is based on a set of differential equations. Variations in plasma insulin concentration $(I)$ can be estimated by Equation (1).

$$
\frac{d I}{d t}=\frac{I_{a b s}}{V_{i}}-k_{e} \cdot I
$$

where $I_{a b s}$ represents the rate of insulin absorption, $V_{i}$ is the volume of insulin distribution, and $k_{e}$ is the first-order rate constant of insulin elimination. The absorption of insulin can be calculated as follows:

$$
I_{a b s}=\frac{s t^{2} T_{50}^{s} D}{t\left(T_{50}^{s}+t^{s}\right)^{2}}
$$

where $s$ is a parameter associated with the insulin absorption pattern, $t$ represents the time of the injection, $T_{50}$ is when the dose (D) is absorbed in an amount of $50 \%$. 
3. To estimate steady-state conditions, insulin profile $\left(I_{s S}\right)$ using the superposition principle is computed assuming three days as follows:

$$
\begin{gathered}
I_{s S}(t)=\mathrm{I}(t)+I(t+24)+I(t+48) \\
I_{a, s s}(t)=\mathrm{I}_{a}(t)+I_{a}(t+24)+I_{a}(t+48)
\end{gathered}
$$

where $I_{a}$ is the build-up and the deactivation of the insulin pump.

4. Meal Intake model: this model was proposed in 1992 by Lehmann and Deutsch [43]. It describes the gastric glucose absorption into the bloodstream by a meal intake represented by its carbohydrates content. According to this model, glucose utilization $G_{\text {out }}(G)$ at plasma insulin concentration is:

$$
G_{\text {out }}(G)=\frac{V_{\max } G}{k_{m}+G}
$$

$G$ represents the glucose concentration, $V_{\max }$ maximal glucose utilization for reference insulin concentration, and $K_{m}$ is glucose concentration for the half-maximal response. $V_{\max }$ depends on insulin; mathematically, this is

$$
V_{\max }\left(I_{\text {ss }}\right)=\frac{G_{\text {out }}\left(I_{\text {ss }}\right)\left(K_{m}+G_{x}\right)}{G_{x}}
$$

where $I_{S S}$ is plasma insulin concentration equivalent to steady-state insulin, and $G_{x}$ is the reference glucose value. Glucose utilization for any combination of plasma glucose and insulin levels is given by

$$
G_{\text {out }}\left(G, I_{s s}\right)=\frac{G\left(c \cdot I_{s S}+d\right)\left(K_{m}+G_{x}\right)}{G_{x}\left(K_{m}+G\right)}
$$

where $c$ is insulin sensitivity, and $d$ represents insulin-independent glucose utilization. The insulin absorption dynamics for regular, NPH, lente, ultralente formulations were characterized in [42] just by changing some specific parameters in the general model. Recently, in [44], the Lispro insulin formulation was also characterized by the model in [42].

5. The exercise model was considered from [41]. The liver's glycogen reservoir (GLY) can be calculated as shown in Equation (8).

$$
\begin{gathered}
\frac{d G L Y(t)}{d t}=-\varnothing\left(P V O_{2}^{\max }(t), G L Y(t)\right)+\Psi\left(G_{a b s}(t)+G L Y(t)\right) \\
\varnothing\left(P V O_{2}^{\max }, G L Y\right)=\left\{\begin{array}{rll}
\zeta\left(P V O_{2}^{\max }\right) & \text { if } & 0<G L Y \leq G L Y_{\max } \\
0 & \text { if } \quad G L Y \geq 0
\end{array}\right. \\
\Psi\left(G_{a b s}, G L Y\right)=\left\{\begin{array}{ccc}
G_{a b s} & \text { if } & G L Y<G L Y_{\max } \\
0 & \text { if } & G L Y>G L Y_{\max }
\end{array}\right. \\
\zeta\left(P V O_{2}^{\max }\right)=0.006\left(P V O_{2}^{\max }\right)^{2}+1.226 P V O_{2}^{\max }-10.1958 \mathrm{mg} / \mathrm{min}
\end{gathered}
$$

where $\varphi$ is the net glycogenolysis rate, $\Psi$ represents the absorptive period, $\zeta$ is the glucose uptake due to exercise intensity, and $\mathrm{PVO}_{2}{ }^{\mathrm{max}}$ is the percentage of the maximum oxygen consumption rate.

In Figure 1, the block diagram of the diabetic patient utilized in this work is shown. There are four subsystems, each one corresponds to a previously described model, and their interactions are shown as solid arrows. The dotted lines delimit the mathematical models proposed in the literature, which describe different but comparable physiological phenomena because they have the same scale. 


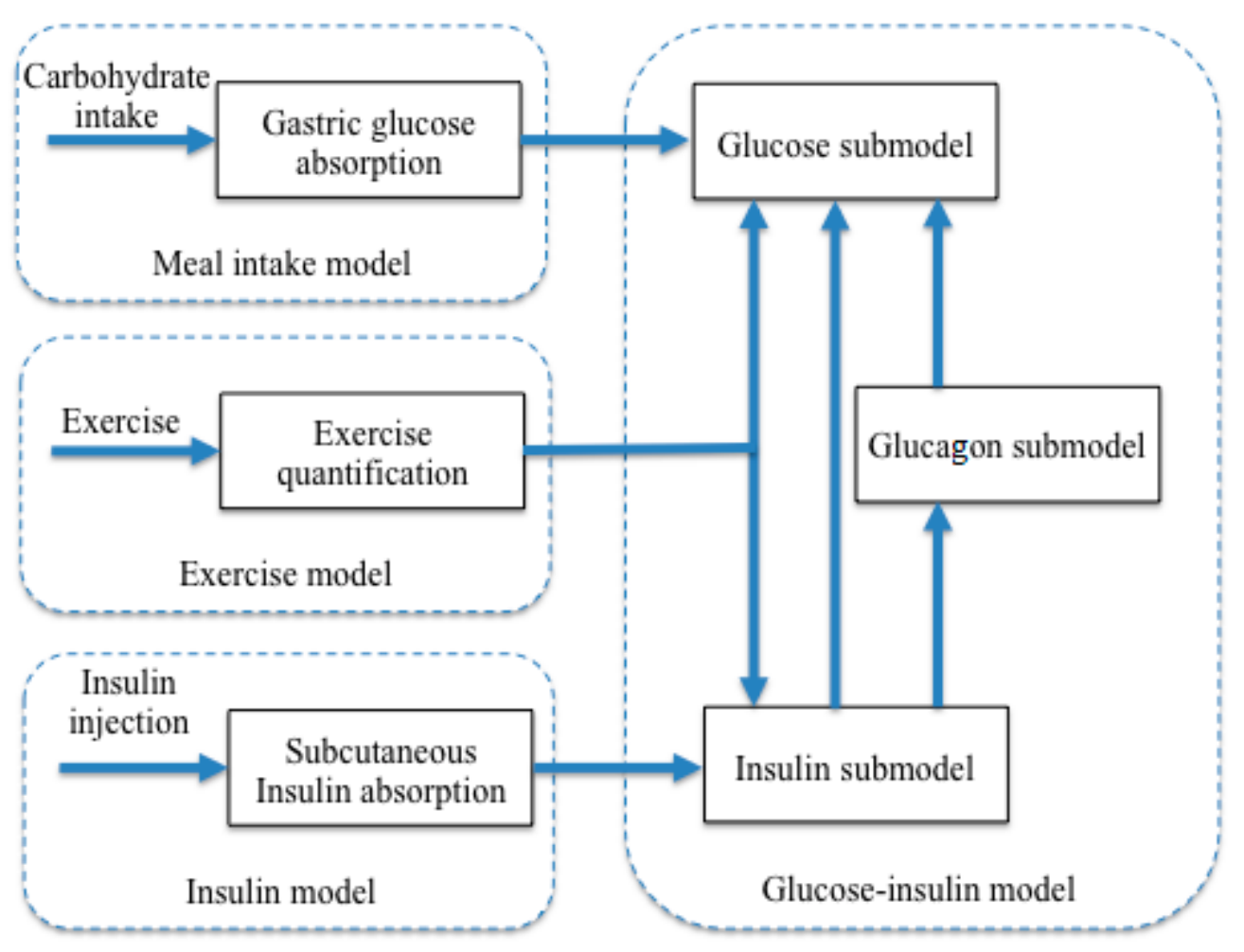

Figure 1. The diabetic patient model utilized for the implementation of simulations reported in this work.

\section{Results and Discussion}

\subsection{Mobile Application for Educational Similar}

\subsubsection{Hardware and Software Tools}

The proposed education simulator was developed based on the models described in the last section. The models were implemented in Java using Android Studio IDE with Android Studio SDK and Java SE Development Kit; besides, Android MPChart Library is used for showing results of the glucose level simulation in a plot [45].

The proposed application was validated on devices with several versions of Android. Table 1, shows the list of devices and its specifications used for testing the proposed application.

Table 1. Devices utilized for testing the proposed application.

\begin{tabular}{cccc}
\hline Device & Processor & RAM & Android Version \\
\hline Galaxy S2 & Dual-core 1.2 GHz Cortex-A9 & 1 GB & 4.1 \\
Galaxy S4 & Dual-core 1.7 GHz Krait 300 & $1.5 \mathrm{~GB}$ & 5.0 .1 \\
Polaroid Tab & Dual-core 1.0 GHz Broadcom 21663 & $1 \mathrm{~GB}$ & 4.2 .2 \\
Galaxy Tab 10.1 & Quad-core 2.3 GHz Krait 400 & $3 \mathrm{~GB}$ & 5.1 .1 \\
LG G3 Stylus & Quad-core 1.3 GHz Cortex-A7 & $1 \mathrm{~GB}$ & 5.0 .2 \\
\hline
\end{tabular}

\subsubsection{System Architecture}

In Figure 2, the architecture of the proposed application is shown. The architecture takes as an input the following data:

1. Meal parameters: these parameters are related to carbohydrate intake (in grams) and the day's carbohydrate intake schedule. 
2. Insulin dose parameters: these parameters are related to the type (fast or slow actions) and the dose of insulin (in units).

3. Exercise parameters: these parameters are related to the quantity and intensity of exercise.

4. Simulation configuration: these parameters are related to the simulation's duration and the type of plot to be generated.

5. The architecture contains the following blocks:

6. Simulation variables container: this block stores data required to be accessed and shared by all model blocks. It contains three profiles: meal dosing, insulin dosing, and exercise quantification.

7. Meal model block: this block takes as input the meal profile and generates as output the glucose obtained according to the carbohydrate intake grams.

8. Insulin model block: this block takes as input the insulin dosing profile and generates as output the quantity and duration of insulin in the blood flow.

9. Exercise model block: this block takes as input the exercise dosing profile and generates as output the blood redistribution volume according to the quantity of exercise.

10. Simulation loop block: this block updates each model block with required data from others and controls the simulation's start and end.

11. Plot generation module: this block generates data from the simulation to be used for generating a plot.

12. Plot visualization module: this block takes as input the vector generated by the plot generation module and displays the plot.

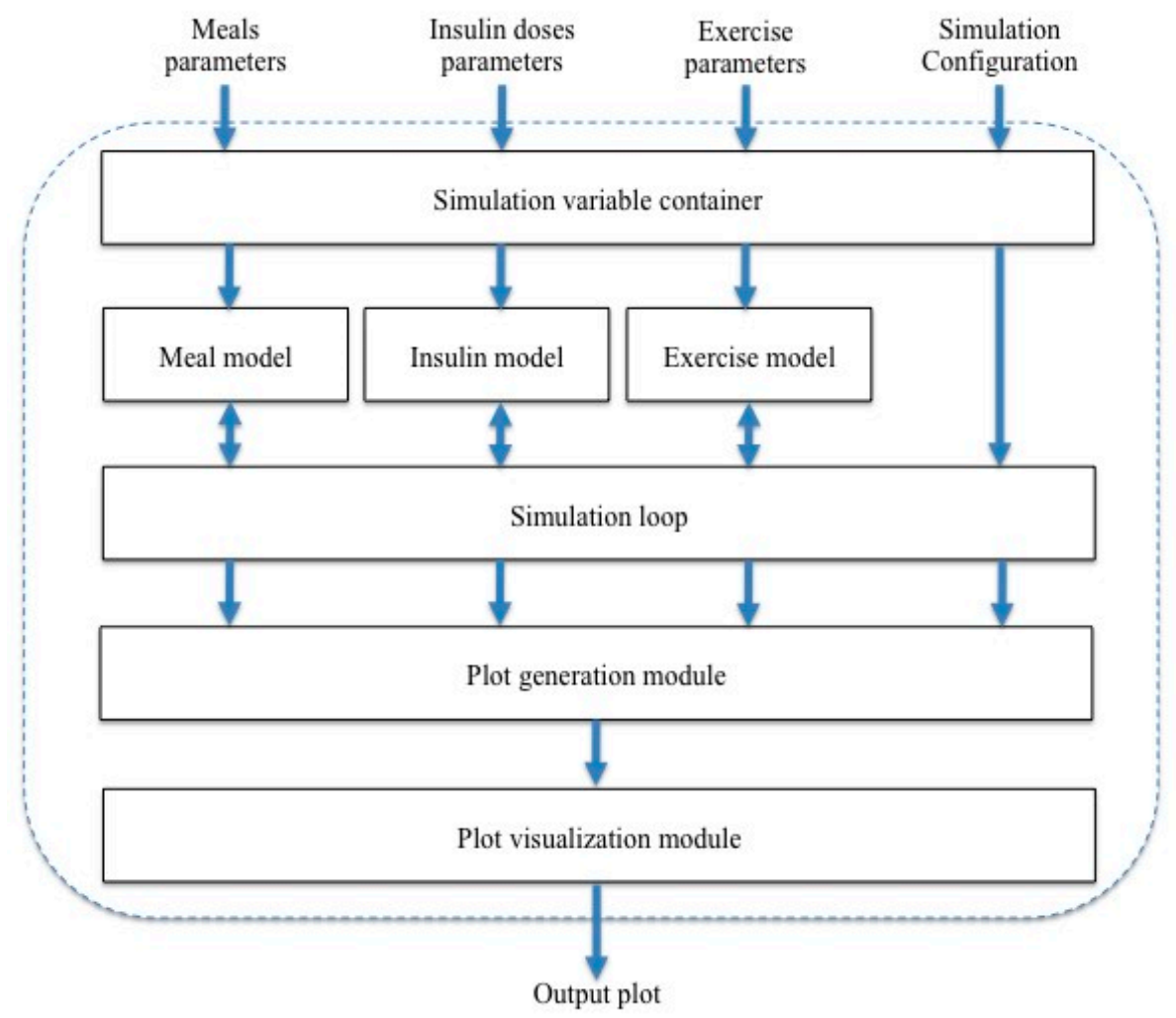

Figure 2. The system architecture.

Finally, the architecture generates as the output the plot with the information according to the user's input. 


\subsubsection{User Interface}

In Figure 3a, a welcome screen of the proposed application is shown. The proposed application's main objective is the generation of a plot of the blood glucose concentration based on the parameters defined in the previous section. For user commodity and better distribution application's controls, a tabbed document interface (TDI) was conceived as the main container for hosting all the needed user controls required to set the simulation parameters and show the results. Specifically, for the Android SDK environment, a tab host container was utilized. This control enables the integration of plenty of components in a single form. The proposed application contains four tabs: the first three tabs allow the user to define the parameters of meal, insulin, and exercise models, and the last one is designed to generate simulation data and show the blood glucose concentration in a plot.

a)

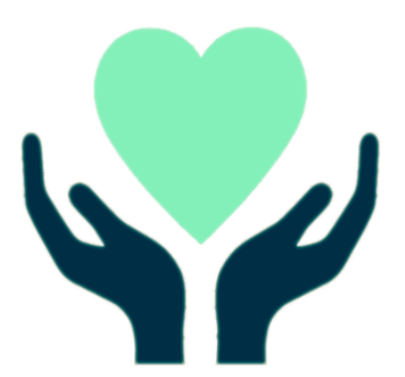

A E D M A

(App Educational Diabetes Management Advisor)

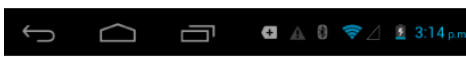

b)

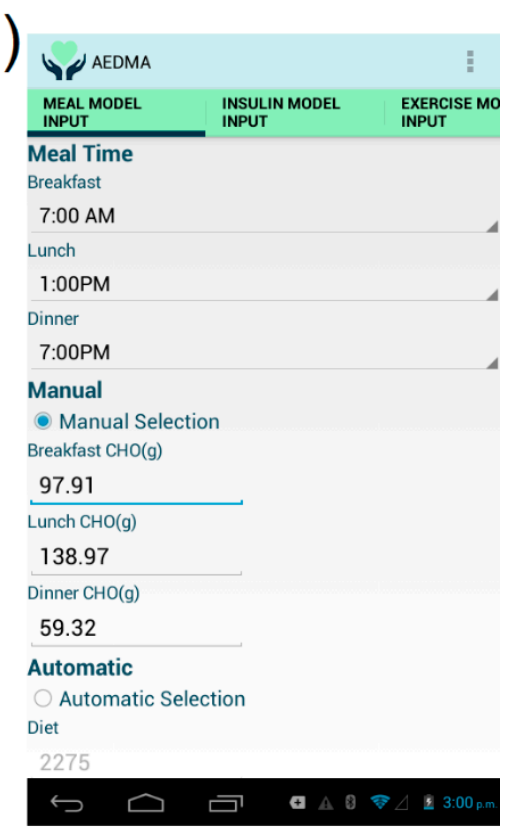

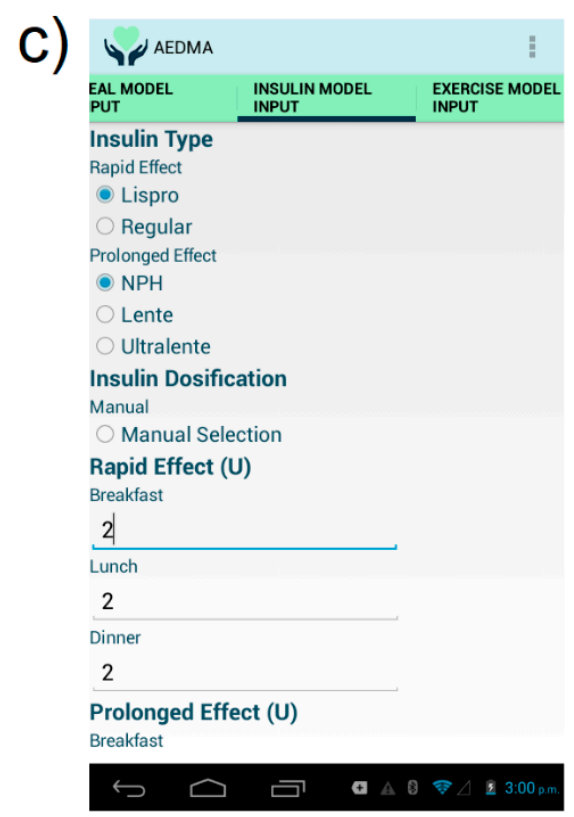

Figure 3. Screens of the proposed AEDMA app. (a) Main screen of the proposed applications. (b) Components of the meal model input Table. (c) Components of the insulin model tab. 
In Figure $3 b$, the tab for the meal model parameters is shown. This tab contains interface controls where users can define each meal's time and its estimated carbohydrate contents (in grams). The estimated carbohydrate contents also can be automatically calculated based on a default estimation of calories for a day, or user can input the total calories, and the application estimates the carbohydrate content in grams based on the given calories.

In Figure 3c, the tab for the insulin model is shown. This tab contains interface controls that define the type of insulin and the unit to be dosed in each meal, for both the rapid and prolonged effect.

In Figure $4 \mathrm{a}$, the tab for the exercise model is shown. This tab contains interface controls where the user defines the intensity, duration, start time, and exercise routine.

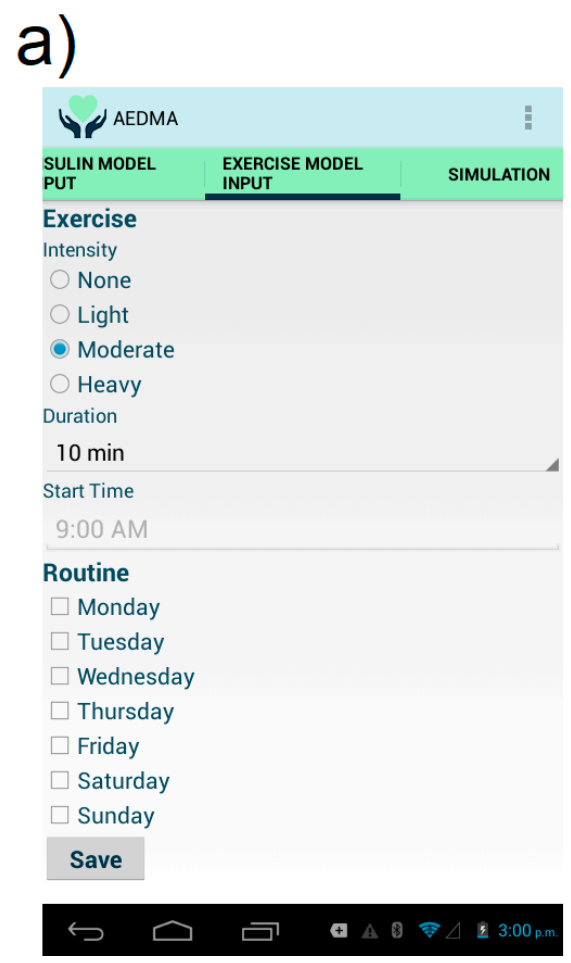

Figure 4. The last two configuration screens. (b) Components of the simulations tab.

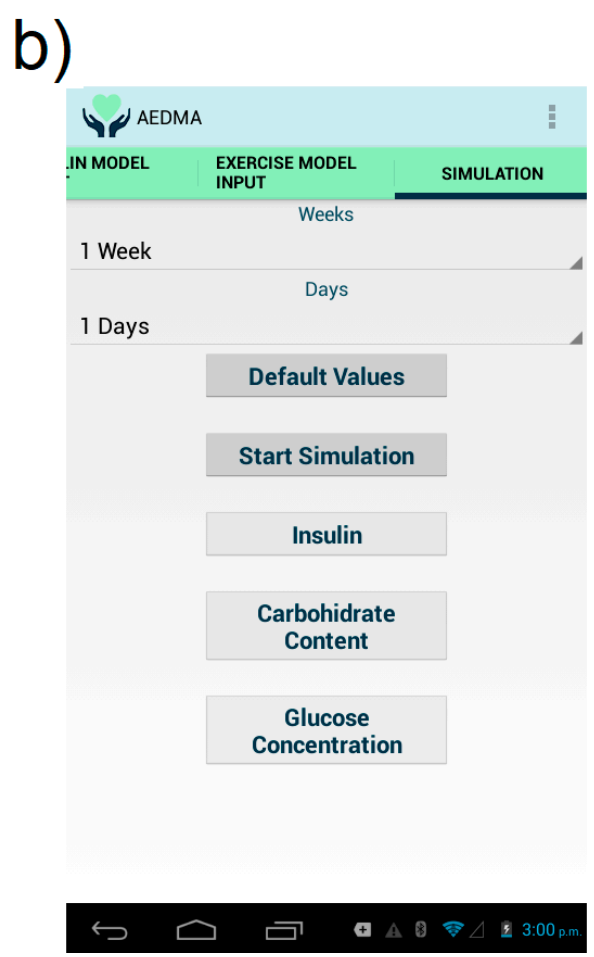

(a) Components of the exercise model Table.

In Figure $4 \mathrm{~b}$, the tab for simulation is shown. In this tab, the user defines the time of the simulation in weeks and days. It is also possible to set all variables to their default values, start simulation, shown insulin, carbohydrate, or glucose concentration plots.

In Table 2, the application's default values are listed, but the user can syntonize this to get a better understanding of the model behavior.

Table 2. Default parameter values for the proposed application.

\begin{tabular}{cc}
\hline \multicolumn{2}{c}{ Meal Model } \\
\hline Breakfast time & $7: 00 \mathrm{AM}$ \\
Lunch time & $1: 00 \mathrm{PM}$ \\
Dinner time & $7: 00 \mathrm{PM}$ \\
Breakfast CHO $(\mathrm{g})$ & 97.91 \\
Lunch CHO $(\mathrm{g})$ & 138.97 \\
Dinner CHO $(\mathrm{g})$ & 59.32 \\
\hline
\end{tabular}


Table 2. Cont.

\begin{tabular}{cc}
\hline \multicolumn{2}{c}{ Insulin Model } \\
\hline Rapid effect insulin type & Lispro \\
Prolonged effect insulin Type & NPH \\
Rapid effect insulin units at breakfast & 2 \\
Rapid effect insulin units at lunch & 2 \\
Rapid effect insulin units at dinner & 2 \\
Prolonged effect insulin units at breakfast & 3 \\
Prolonged effect insulin units at dinner & 3 \\
\hline Exercise Model & \\
\hline Intensity & Light \\
Duration & 10 min \\
Start time & $9: 00 \mathrm{AM}$ \\
Routine & Monday checked \\
\hline
\end{tabular}

\subsection{Reported Experiments}

In Table 3, the parameters utilized for validating the meal and insulin models are shown. The abbreviations in the column names are experiment number (Exp), carbohydrate grams in breakfast

Table 3. Selected parameters set of four experiments.

\begin{tabular}{|c|c|c|c|c|c|c|c|c|c|c|c|}
\hline \multirow{3}{*}{ Exp } & \multicolumn{10}{|c|}{ Meal } & \multirow{3}{*}{$\begin{array}{c}\text { Insulin } \\
\text { Dossification }\end{array}$} \\
\hline & \multicolumn{3}{|c|}{ Carbohydrate Grams Intake } & \multicolumn{3}{|c|}{ Rapid Effect } & \multicolumn{4}{|c|}{ Prolongated Effect } & \\
\hline & B-CHO & L-CHO & D-CHO & Type & B-u & L-u & D-u & Type & B-u & D-u & \\
\hline 1 & 97.91 & 138.97 & 59.32 & Lispro & 2 & 2 & 2 & $\mathrm{NPH}$ & 3 & 3 & \\
\hline 2 & 49.85 & 69.48 & 29.66 & Lispro & 2 & 2 & 2 & $\mathrm{NPH}$ & 3 & 3 & \\
\hline 3 & 97.91 & 138.97 & 59.32 & Lispro & 4 & 4 & 4 & $\mathrm{NPH}$ & 6 & 6 & \\
\hline 4 & 49.85 & 69.48 & 29.66 & Lispro & 4 & 4 & 4 & $\mathrm{NPH}$ & 6 & 6 & \\
\hline
\end{tabular}

(B-CHO), carbohydrate grams in lunch (L-CHO), carbohydrate grams in dinner (D-CHO), insulin units at breakfast (B-u), insulin units at lunch ( $\mathrm{L}-\mathrm{u})$, insulin units at dinner (D-u). In the first experiment, the default values for carbohydrate and insulin units are used. In the second experiment, carbohydrate grams are reduced to half, but the insulin units are left at their default values. In the third experiment, default values for carbohydrate grams are used, but the insulin dose is doubled, and in the last experiment, carbohydrate grams are reduced to half, and the insulin dose is doubled.

Figure 5 shows a glucose concentration plot for a 5-day simulation for each experiment reported in Table 3. In Figure 5a, the maximum glucose peak is close to $195 \mathrm{mg} / \mathrm{dL}$ every day of the reported simulation. In contrast, in Figure $5 \mathrm{~b}$, the maximum glucose peak surpasses $175 \mathrm{mg} / \mathrm{dL}$ due to the reduction of carbohydrate intake. In Figure $5 c$, the same carbohydrate intake is used, but both prolonged and rapid insulin doses are doubled. It can be shown that glucose levels are lower when compared with the plot of experiment 1 , and in Figure $5 \mathrm{~d}$, also the carbohydrate intake is reduced to half to validate both meal and insulin models. In both experiments ( 3 and 4 ), it can be shown for its corresponding plots that even a risk of hyperglycemia is present due to the high insulin dose. 
a)

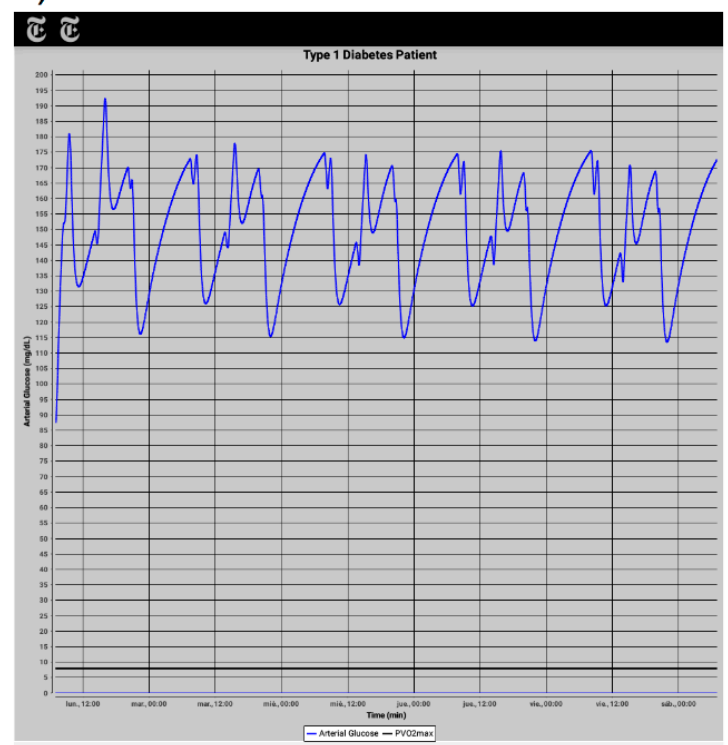

c)

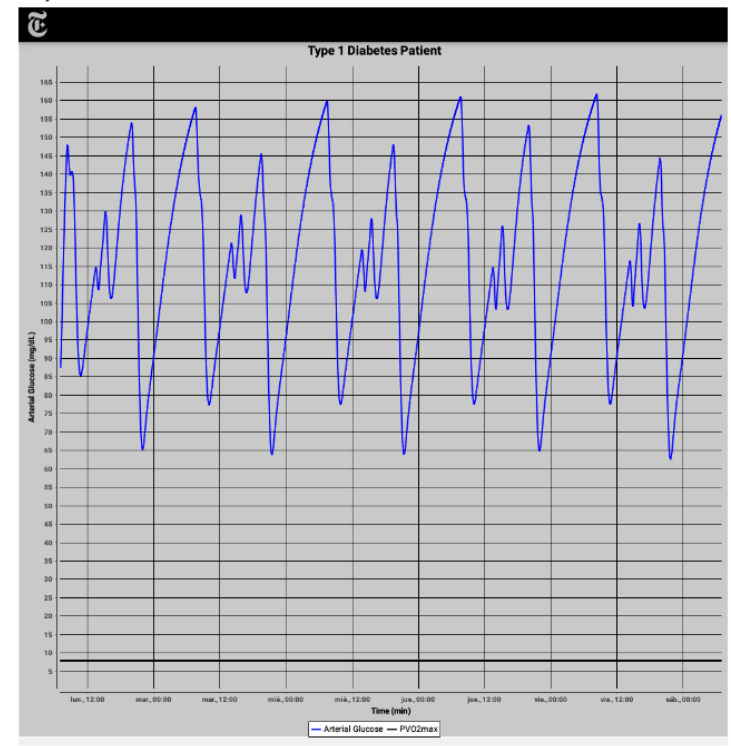

b)

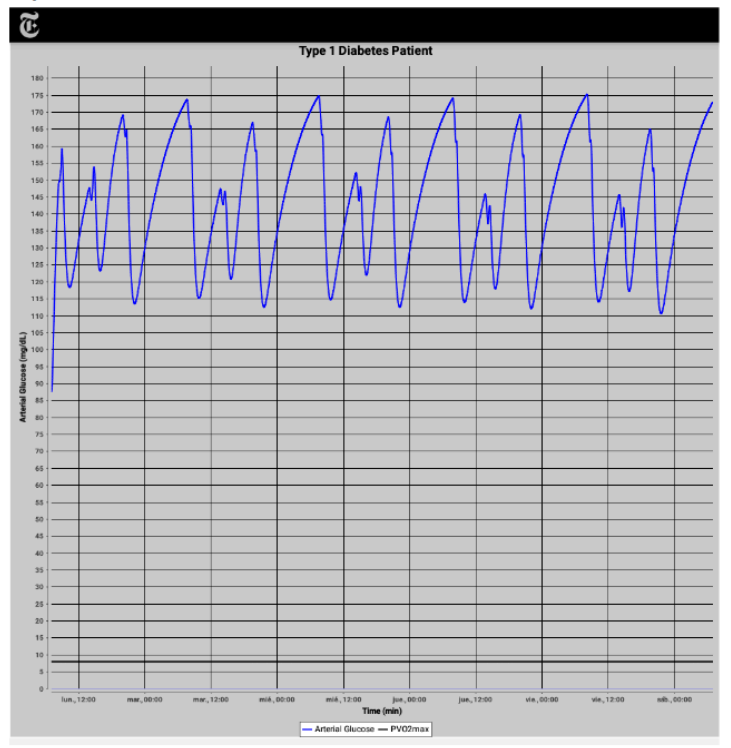

d)

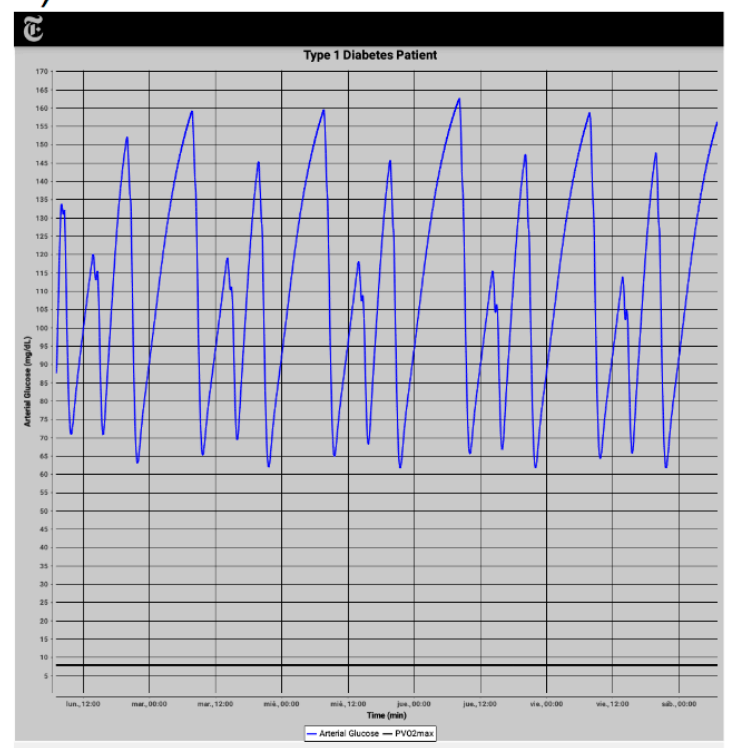

Figure 5. Comparison of blood glucose plots generated by AEDMA application for several values of carbohydrate grams and insulin units. (a) Experiment 1. (b) Experiment 2. (c) Experiment 3. (d) Experiment 4.

In Figure 6, a validation of the exercise models through the corresponding simulation plots are shown. In order to obtain the reported plots, the used exercise intensities are light, moderate, and heavy, and the exercise durations are 10, 30, and $90 \mathrm{~min}$. The default values for grams of carbohydrate intake and insulin doses are used. In Figure 6a, the simulation using $10 \mathrm{~min}$ of light exercise is shown. The value of the glucose peaks after exercise (at 9:00 AM) is close to $185 \mathrm{mg} / \mathrm{dL}$, but using $30 \mathrm{~min}$ of light exercise, this is under $180 \mathrm{mg} / \mathrm{dL}$ (Figure 6b), and when using $90 \mathrm{~min}$ of light exercise, the glucose peaks is close to $175 \mathrm{mg} / \mathrm{dL}$ (Figure 6c). Similar behavior is shown when using the same duration but with moderate exercise (Figure $6 d-f$ ). The value of the glucose peaks after exercise (at 9:00 AM) is close to $175 \mathrm{mg} / \mathrm{dL}$, and it is low when compared with the same peak obtained when using light exercise $(180 \mathrm{mg} / \mathrm{dL})$. Finally, this behavior remains when using heavy exercise (Figure $6 \mathrm{~g}-\mathrm{i})$. For comparing exercise intensities, it can be shown from plots that the glucose peaks after $10 \mathrm{~min}$ exercise are: close to 
$185 \mathrm{mg} / \mathrm{dL}$ for light exercise, over $175 \mathrm{mg} / \mathrm{dL}$ for moderate exercise, and below $170 \mathrm{mg} / \mathrm{dL}$ for heavy exercise. Similar results are obtained for 30 and $90 \mathrm{~min}$ of exercise duration. In general, there are many applications, however, long-term prediction of glucose still remains a challenge [20]. In this work, an app has been developed capable of predicting the behavior of glucose levels for several days (see Figure 5) or during a day with different exercise regimes (see Figure 6).

a)

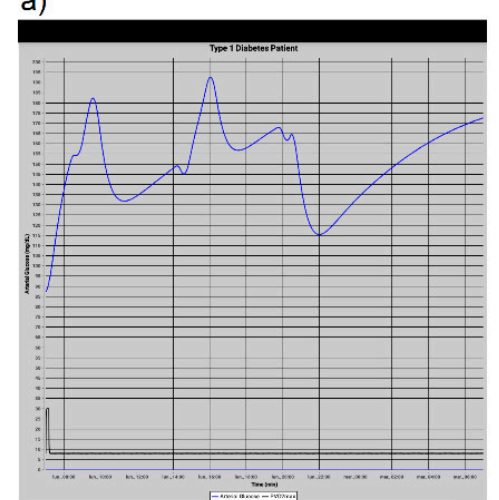

d)

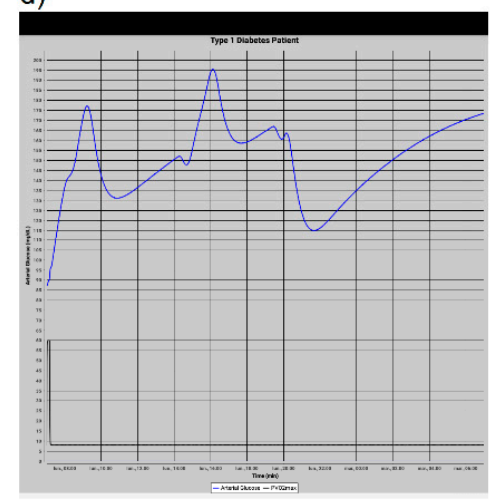

g)

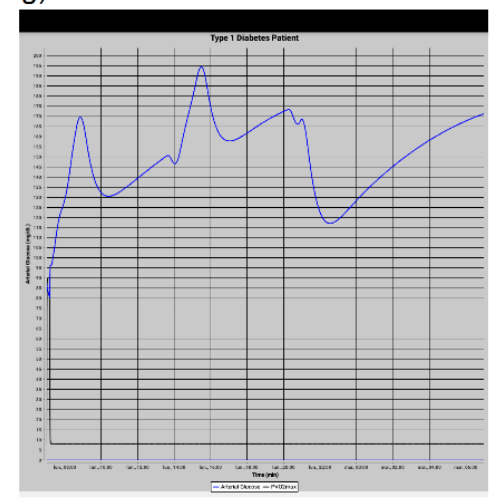

b)

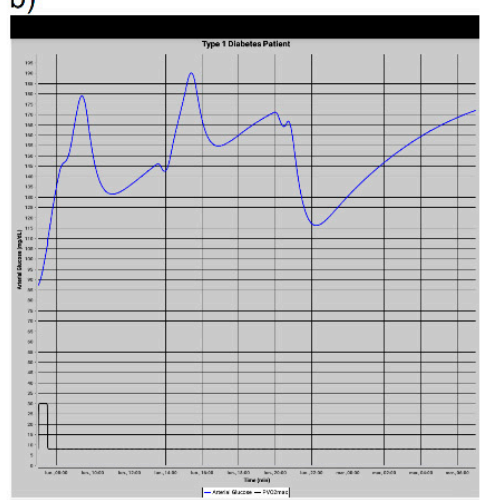

e)

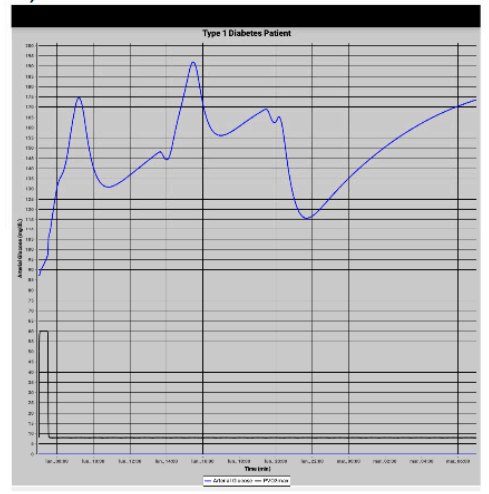

h)

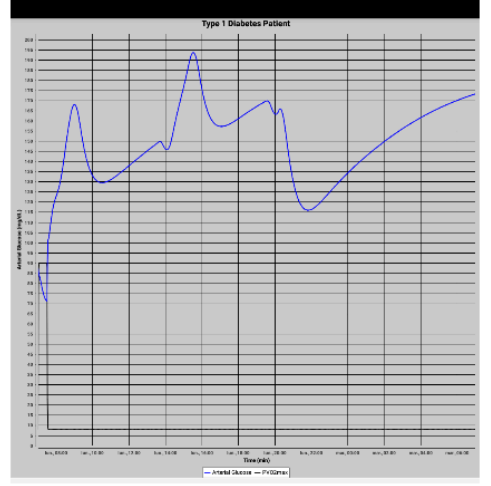

c)

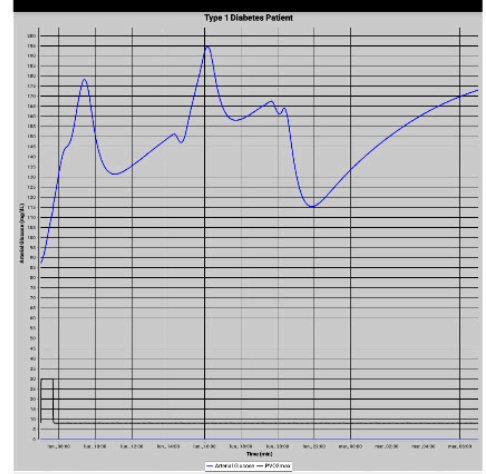

f)

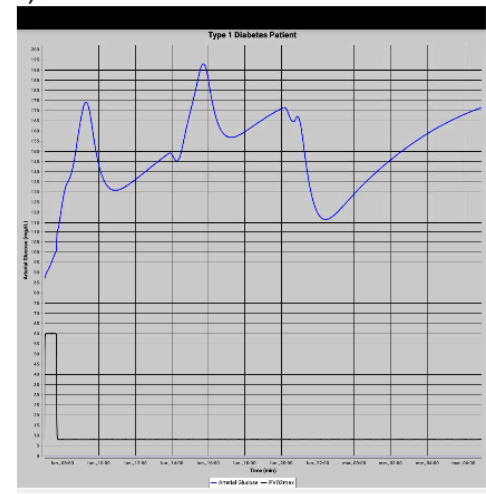

i)

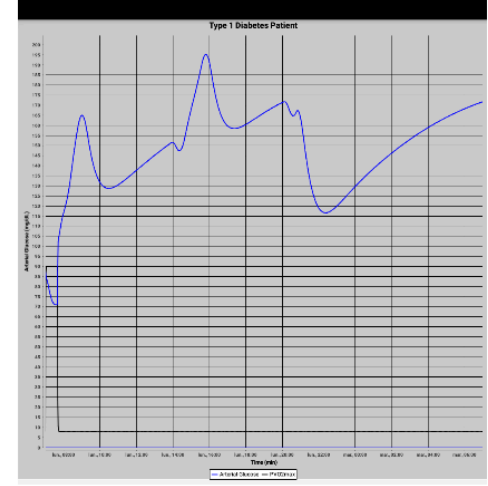

Figure 6. Comparison of blood glucose plots generated by AEDMA application for several exercise intensities using experiment 1 settings. (a) Light exercise-10 min. (b) Light exercise-30 min. (c) Light exercise-90 min. (d) Moderate exercise-10 min. (e) Moderate exercise-30 min. (f) Moderate exercise $-90 \mathrm{~min}$. (g) Heavy exercise-10 $\mathrm{min}$. (h) Heavy exercise-30 min. (i) Heavy exercise—90 min.

Until now, the complete software of the presented application has not been compared with other applications since our priority is to focus on the diet and physical activity of the Mexican population with diabetes. There are many applications, but with European or United States standards. However, each submodel has been compared and validated separately by its respective authors. It is important to point out that the current version of the application presented in this work is an extension of a 
previous compartmental model that takes into account exercise periods. This model was developed by the main author, who validated and compared its results with experimental data [41]. So far, we have performed a prototype test on 26 young adults and execution times comparison for different devices.

\subsection{Qualitative Study}

For validating the AEDMA, we perform a prototype test using a questionnaire to evaluate the main points of the proposed system. We applied a questionnaire to 26 young adults (age 15-25). This application is focused mainly on this user group, which is highly familiar with tablet or smartphone devices, and they are regular users of mobile apps. We restrict the participants of the prototype test to have an android device because we designed AEDMA specifically for this mobile OS. In Table 4, relevant information about the distribution of the testing subjects is shown.

Table 4. Relevant data of testing subjects.

\begin{tabular}{cccccc}
\hline \multicolumn{2}{c}{ Gender } & \multicolumn{2}{c}{ Age } & \multicolumn{2}{c}{$\begin{array}{c}\text { Previous Knowledge of Mobiles } \\
\text { Apps for Diabetes Treatment }\end{array}$} \\
\hline Male & Female & $15-19$ & $20-25$ & Yes & No \\
$76.9 \%$ & $23.1 \%$ & $38.5 \%$ & $61.5 \%$ & $15.4 \%$ & $84.6 \%$ \\
\hline
\end{tabular}

After testing the ADEMA by at least $1 \mathrm{~h}$ in the participant's device, they were asked to answer a questionnaire that contains 10 questions related to the key aspects of the AEDMA. Each question has 5 options, rated from NO, Rather NO, Do not know, Rather YES, and YES. The questions and the percentage of responses for each option are summarized in Table 5. From the obtained responses, we can summarize the following remarks:

1. From questions $1,3,4$, and 5, a preliminary conclusion about important points to be improved to the AEDMA can be guessed. These points are related to improving the user interface, the clarity, and legibility of presented glucose level graphs, and the ease of use of the app. Question 8 gives a general panorama showing that the mobile app in its current state can be improved. From question 9, the variability of glucose levels is adequate from the user's perspective.

2. In general, from questions 2 and 7, we can conclude that the AEDMA is useful and to give an appropriate impression to the test user, to reuse the application if a next version is released. Question 10 allows highlighting the importance of giving users an important role to involve them in the design of these types of apps.

Table 5. Results of the questionnaire for the test group.

\begin{tabular}{|c|c|c|c|c|c|}
\hline Question & $1(\mathrm{No}) \%$ & $\begin{array}{l}2 \text { (Rather } \\
\text { No) } \%\end{array}$ & $\begin{array}{l}3(\text { Do Not } \\
\text { Know) } \%\end{array}$ & $\begin{array}{l}4 \text { (Rather } \\
\text { Yes) \% }\end{array}$ & $5($ Yes $) \%$ \\
\hline $\begin{array}{l}\text { (1) Are the user interface controls adequate to the type of data } \\
\text { required by the app? }\end{array}$ & $15.4 \%$ & $15.4 \%$ & $15.4 \%$ & $38.5 \%$ & $15.4 \%$ \\
\hline (2) Is the application useful? & $23.1 \%$ & $0 \%$ & $0 \%$ & $0 \%$ & $76.9 \%$ \\
\hline (3) Are the generated graphs easy to understand? & $7.7 \%$ & $0 \%$ & $23.1 \%$ & $46.2 \%$ & $23.1 \%$ \\
\hline $\begin{array}{c}\text { (4) Do the application's user interface controls allow to } \\
\text { manage the application in an ease way? }\end{array}$ & $0 \%$ & $7.7 \%$ & $7.7 \%$ & $46.2 \%$ & $38.5 \%$ \\
\hline (5) How difficult has been the use of the app? & $15.4 \%$ & $38.5 \%$ & $30.8 \%$ & $15.4 \%$ & $0 \%$ \\
\hline $\begin{array}{l}\text { (6) Does the application motivate to study more in depth the } \\
\text { phenomena? }\end{array}$ & $0 \%$ & $0 \%$ & $15.4 \%$ & $46.2 \%$ & $38.5 \%$ \\
\hline (7) Will you reuse the app? & $0 \%$ & $7.7 \%$ & $7.7 \%$ & $15.4 \%$ & $69.2 \%$ \\
\hline (8) Do you consider that current app can be improved? & $7.7 \%$ & $0 \%$ & $0 \%$ & $23.1 \%$ & $69.2 \%$ \\
\hline $\begin{array}{l}\text { (9) Do you consider appropriate the functionality of the } \\
\text { application for learning the glucose levels variability? }\end{array}$ & $0 \%$ & $0 \%$ & $7.7 \%$ & $38.5 \%$ & $53.8 \%$ \\
\hline $\begin{array}{l}\text { (10) Do you consider the mobile application are sufficient to } \\
\text { assess whether in the future you would like to participate in } \\
\text { similar experiences with mobile apps? }\end{array}$ & $0 \%$ & $0 \%$ & $23.1 \%$ & $38.5 \%$ & $38.5 \%$ \\
\hline
\end{tabular}




\subsection{Execution Time Comparison}

We obtain a measurement of the time required to conclude the simulation using several parameters for each application's deployment device. Table 6 shows the obtained measurements for each device. We compute each measurement using only one thread environment because a multithread environment was not conceived in the original application. We choose the following simulation times: 4 days, one week, two weeks, and three weeks. A Polaroid tablet device obtained the biggest execution time, while a Galaxy Tab 10.1 device obtained the shortest one. The rows in Table 6 start from the slower to the higher simulation time. The mobile devices used for the application's deployment were not recent models, because even when some of them were featured as high-end devices when released, they are old devices and, with recent advances in mobile technology, many of them can be featured as low or middle-end devices when compared with the existing technology available at the time of writing this paper.

Table 6. Time to complete computation of glucose concentration plots (in seconds) using several simulation time durations.

\begin{tabular}{ccccc}
\hline \multirow{2}{*}{ Device } & \multicolumn{4}{c}{ Simulation Time Duration } \\
\cline { 2 - 5 } & 4 Days & 1 Week & 2 Weeks & 3 Weeks \\
\hline Polaroid Tab & 12.30 & 13.53 & 16.24 & 21.11 \\
Galaxy S2 & 9.53 & 10.97 & 13.16 & 18.16 \\
Galaxy S4 & 6.53 & 7.64 & 9.17 & 12.84 \\
LG G3 Stylus & 5.53 & 6.59 & 7.90 & 11.30 \\
Galaxy Tab 10.1 & 5.53 & 6.70 & 8.04 & 11.73 \\
\hline
\end{tabular}

\section{Conclusions}

In this paper, an application for diabetes education is proposed. The proposed application was designed to provide a software tool to help support therapy in patients with diabetes, seeking to improve the quality of life. The simulation is fixed, but an interactive simulation functionality can be added to provide a richer user experience. The software is based on four mathematical models originally designed as a desktop computer program. An exercise option in the interface helps patients to schedule their routines and to estimate in advance its impact on blood glucose. This app could also be developed for Apples' iOS products. Besides, this app could potentially be implemented as a smartwatch app. The most important conclusions are:

1. The App includes glucose regulation associated with metabolism and the application of an insulin injection.

2. The App is capable of taking into account the effects of food intake and physical activity.

3. The developed application can simulate the behavior of glucose levels for long periods.

4. The App is capable of considering three types of physical activity: light, moderate and heavy.

5. The developed application is focused on type-1 diabetes, but this can be extended to consider type-2 diabetes.

6. As a future improvement, the application should be modified to split the simulation processing into smaller operations running on multiple threads. This could be beneficial in devices with more than one core.

Author Contributions: Conceptualization, M.H.-O., M.A.N.-M.; Formal Analysis, C.A.C.-A., A.R.-L.; Investigation, M.A.N.-M., G.E.O.-C., J.M.C.-C.; Methodology, M.H.-O., C.A.C.-A., G.E.O.-C., R.S.-H., O.M.-R.; Project Administration, M.H.-O., R.S.-H.; Software, M.H.-O., G.E.O.-C., J.M.C.-C., O.M.-R.; Supervision, M.H.-O., M.A.N.-M., A.R.-L., O.M.-R.; Validation, A.R.-L., R.S.-H., J.M.C.-C.; Visualization, A.R.-L., J.M.C.-C., O.M.-R.; Writing Original Draft, M.H.-O., M.A.N.-M., C.A.C.-A., G.E.O.-C.; Writing Review and Editing, M.A.N.-M., C.A.C.-A., R.S.-H. All authors have read and agreed to the published version of the manuscript.

Funding: This research received no external funding. 
Acknowledgments: The present project was partially funded by the National Council of Science and Technology of México (CONACYT) through a scholarship (no. 337087) granted to José Margarito Canseco-Cortinas. The authors are grateful for the support provided by TNM-ITV, CONACYT and PRODEP.

Conflicts of Interest: The authors declare no conflict of interest.

\section{References}

1. World Health Organization. Obesity and Overweight Fact Sheet; WHO: Geneva, Switzerland, 2016.

2. World Health Organization. Diabetes Fact Sheet; WHO: Geneva, Switzerland, 2016.

3. Institute for Health Metrics and Evaluation. The Global Burden of Disease: Generating Evidence, Guiding Policy; IHME: Washington, DC, USA, 2013.

4. World Health Organization. The Top 10 Causes of Death; WHO: Geneva, Switzerland, 2017.

5. International Diabetes Federation. IDF Diabetes Atlas, 7th ed.; International Diabetes Federation: Brussels, Belgium, 2015.

6. Levy, T.S.; Nasu, L.C.; Dommarco, J.R.; Ávila, M.H. Informe Final de Resultados, Encuesta Nacional de Salud y Nutrición de Medio Camino 2016; Instituto Nacional de Salud Pública INSP: Mexico City, Mexico, 2016.

7. Institute for Health Metrics and Evaluation (IHME). Country Profile Mexico. Mexico, 2017. Available online: http://www.healthdata.org/ (accessed on 7 October 2018).

8. Statista Inc. Global Smartphone Sales to End Users 2007-2016. Available online: https://www.statista.com/ statistics/263437/global-smartphone-sales-to-end-users-since-2007/ (accessed on 12 October 2018).

9. eMarketer. Worldwide Internet and Mobile Users: eMarketer's Updated Estimates and Forecast for 2015-2020. 2016. Available online: https://www.emarketer.com/Report/Worldwide-Internet-Mobile-UserseMarketersUpdated-Estimates-Forecast-20152020/2001897\#moreReport (accessed on 25 September 2018).

10. Lehmann, E. Preliminary experience with the Internet release of AIDA-An interactive educational diabetes simulator. Comput. Methods Programs Biomed. 1998, 56, 109-132. [CrossRef]

11. Hernandez-Ordonez, M.; Montano, O.; Campos-Delgado, D.U.; Palacios, E. Development of an Educational Simulator and Graphical User Interface for Diabetic Patients. In Proceedings of the 2007 th International Conference on Electrical and Electronics Engineering, Mexico City, Mexico, 5-7 September 2007; pp. 82-85. [CrossRef]

12. Lehmann, E.D.; Tarín, C.; Bondia, J.; Teufel, E.; Deutsch, T. Development of AIDA v4.3b Diabetes Simulator: Technical Upgrade to Support Incorporation of Lispro, Aspart, and Glargine Insulin Analogues. J. Electr. Comput. Eng. 2011, 2011, 427196. [CrossRef]

13. Thestrup, J.; Gergely, T.; Beck, P. Exploring new care models in diabetes management and therapy with a wireless mobile eHealth platform. In Wireless Mobile Communication and Healthcare: Second International ICST Conference, MobiHealth 2011, Kos Island, Greece, 5-7 October 2011; Revised Selected Papers; Nikita, K.S., Lin, J.C., Fotiadis, D.I., Arredondo Waldmeyer, M.T., Eds.; Springer: Berlin/Heidelberg, Germany, 2012; pp. 203-210.

14. Erzen, F.C.; Birol, G.; Cinar, A. Glucosim: A simulator for education on the dynamics of diabetes mellitus. In Proceedings of the 23rd Annual International Conference of the IEEE Engineering in Medicine and Biology Society, Istambul, Turkey, 25-28 October 2001; Volume 4, pp. 3163-3166. [CrossRef]

15. Agar, B.U.; Eren, M.; Cinar, A. Glucosim: Educational software for virtual experiments with patients with type 1 diabetes. In Proceedings of the 2005 IEEE Engineering in Medicine and Biology 27th Annual Conference, Shanghai, China, 17-18 January 2006; pp. 845-848. [CrossRef]

16. Mougiakakou, S.G.; Prountzou, K.; Nikita, K.S. A Real Time Simulation Model of Glucose-Insulin Metabolism for Type 1 Diabetes Patients. In Proceedings of the 2005 IEEE Engineering in Medicine and Biology 27th Annual Conference, Shanghai, China, 17-18 January 2005; pp. 298-301. [CrossRef]

17. Bergman, R.N.; Phillips, L.S.; Cobelli, C. Physiologic evaluation of factors controlling glucose tolerance in man: Measurement of insulin sensitivity and beta-cell glucose sensitivity from the response to intravenous glucose. J. Clin. Investig. 1981, 68, 1456-1467. [CrossRef] [PubMed]

18. Cobelli, C.; Caumo, A.; Omenetto, M.; Sacca, L. Minimal model SG overestimation and SI underestimation: Improved accuracy by a Bayesian two-compartment model. Am. J. Physiol. 1999, 277, E481-E488. 
19. Hovorka, R.; Shojaee-Moradie, F.; Carroll, P.V.; Chassin, L.J.; Gowrie, I.J.; Jackson, N.C.; Tudor, R.S.; Umpleby, A.M.; Jones, R.H. Partitioning glucose distribution/trans-port, disposal, and endogenous production during IVGTT. Am. J. Physiol. 2002, 282, E992-E1007.

20. Liu, C.; Vehí, J.; Avari, P.; Reddy, M.; Oliver, N.; Georgiou, P.; Herrero, P. Long-Term Glucose Forecasting Using a Physiological Model and Deconvolution of the Continuous Glucose Monitoring Signal. Sensors 2019, 19, 4338. [CrossRef]

21. Liu, C.; Avari, P.; Leal, Y.; Wos, M.; Sivasithamparam, K.; Georgiou, P.; Reddy, M.; Fernández-Real, J.M.; Martin, C.; Fernández-Balsells, M.; et al. A Modular Safety System for an Insulin Dose Recommender: A Feasibility Study. J. Diabetes Sci. Technol. 2019, 14, 87-96. [CrossRef]

22. Sangeetha, S.; Sreepradha, C.; Sobana, S.; Bidisha, P.; Panda, R.C. Modeling and Control of the Glucose-Insulin-Glucagon System in Type I Diabetis Mellitus. ChemBioEng Rev. 2020, 3, 89-100. [CrossRef]

23. Knopp, J.L.; Hardy, A.R.; Vergeer, S.; Chase, J.G. Modelling insulin adsorption in intravenous infusion sets in the intensive care unit. IFAC J. Syst. Control 2019, 8, 100042. [CrossRef]

24. Visentin, R.; Schiavon, M.; Basu, R.; Basu, A.; Man, C.D.; Cobelli, C. Physiological models for artificial pancreas development. In The Artificial Pancreas: Current Situation and Future Directions, 1st ed.; Sánchez-Peña, R.S., Cherñavvsky, D.R., Eds.; Academic Press: Cambridge, MA, USA, 2019; Volume 1, pp. 123-152.

25. Maas, A.H.; van der Molen, P.; van de Vijver, R.; Chen, W.; van Pul, C.; Cottaar, E.J.; van Riel, N.A.; Hilbers, P.A.; Haak, H.R. Concept Development of the Eindhoven Diabetes Education Simulator Project. Games Health J. 2016, 5, 120-127. [CrossRef]

26. Ristau, R.A.; Yang, J.; White, J.R. Evaluation and Evolution of Diabetes Mobile Applications: Key Factors for Health Care Professionals Seeking to Guide Patients. Diabetes Spectr. 2013, 26, 211-215. Available online: http://spectrum.diabetesjournals.org/content/26/4/211.full.pdf (accessed on 17 September 2018). [CrossRef]

27. El-Gayar, O.; Timsina, P.; Nawar, N.; Eid, W. Mobile Applications for Diabetes Self-Management: Status and Potential. J. Diabetes Sci. Technol. 2013, 7, 247-262. [CrossRef] [PubMed]

28. Chomutare, T.; Fernandez-Luque, L.; Arsand, E.; Hartvigsen, G. Features of mobile diabetes applications: Review of the literature and analysis of current applications compared against evidence-based guidelines. J. Med Internet Res. 2011, 13, e65. [CrossRef] [PubMed]

29. Huckvale, K.; Adomaviciute, S.; Prieto, J.T.; Leow, M.K.S.; Car, J. Smartphone apps for calculating insulin dose: A systematic assessment. BMC Med. 2015, 13, 106. [CrossRef] [PubMed]

30. Cui, M.; Wu, X.; Mao, J.; Wang, X.; Nie, M. T2DM Self-Management via Smartphone Applications: A Systematic Review and Meta-Analysis. PLoS ONE 2016, 11, e0166718. [CrossRef] [PubMed]

31. Garcia, E.; Martin, C.; Garcia, A.; Harrison, R.; Flood, D. Systematic Analysis of Mobile Diabetes Management Applications on Different Platforms. In Proceedings of the 7th Conference on Workgroup Human-Computer Interaction and Usability Engineering of the Austrian Computer Society: Information Quality in e-Health, Graz, Austria, 25-26 November 2011; Springer: Berlin/Heidelberg, Germany, 2011. USAB'11. pp. 379-396.

32. Baskaran, V.; Prescod, F.; Dong, L. A Smartphone-Based Cloud Computing Tool for Managing Type 1 Diabetes in Ontarians. Can. J. Diabetes 2015, 39, 200-203. [CrossRef]

33. Chomutare, T.; Tatara, N.; Arsand, E.; Hartvigsen, G. Designing a diabetes mobile application with social network support. In Studies in Health Technology and Informatics; IOS Press: Clifton, NJ, USA, 2013.

34. Nguyen, H.D.; Jiang, X.; Poo, D.C.C. Designing a Social Mobile Platform for Diabetes Self-management: A Theory-Driven Perspective. In Social Computing and Social Media: 7th International Conference, SCSM 2015, Held as Part of HCI International 2015, Los Angeles, CA, USA, 2-7 August 2015, Proceedings; Meiselwitz, G., Ed.; Springer International Publishing: Cham, Switzerland, 2015; pp. 67-77.

35. Garnweidner-Holme, L.M.; Borgen, I.; Garitano, I.; Noll, J.; Lukasse, M. Designing and Developing a Mobile Smartphone Application for Women with Gestational Diabetes Mellitus Followed-Up at Diabetes Outpatient Clinics in Norway. Healthcare 2015, 3, 310-323. [CrossRef]

36. Borgen, I.; Garnweidner-Holme, L.M.; Jacobsen, A.F.; Bjerkan, K.; Fayyad, S.; Joranger, P.; Lilleengen, A.M.; Mosdøl, A.; Noll, J.; Småstuen, M.C.; et al. Smartphone application for women with gestational diabetes mellitus: A study protocol for a multicentre randomised controlled trial. BMJ Open 2017, 7, e013117. Available online: http://bmjopen.bmj.com/content/7/3/e013117.full.pdf (accessed on 12 December 2018). [CrossRef]

37. Lloyd, B.; Groat, D.; Cook, C.; Kaufman, D.; Grando, A. IDECIDE: A mobile application for insulin dosing using an evidence based equation to account for patient preferences. In Studies in Health Technology and Informatics; IOS Press: Clifton, NJ, USA, 2015; Volume 216, pp. 93-97. [CrossRef] 
38. Keith-Hynes, P.; Mize, B.; Robert, A.; Place, J. The Diabetes Assistant: A Smartphone-Based System for Real-Time Control of Blood Glucose. Electronics 2014, 3, 609-623. [CrossRef]

39. González, A.A.; Voos, H.; Darouach, M. Glucose-Insulin System Based on Minimal Model: A Realistic Approach. In Proceedings of the 2015 17th UKSIM-AMSS International Conference on Modelling and Simulation, Cambridge, UK, 25-27 March 2015; IEEE Computer Society: Washington, DC, USA, 2015. UKSIM '15. pp. 55-60. [CrossRef]

40. Sorensen, J.T. A Physiologic Model of Glucose Metabolism in Man and Its Use to Design and Assess Improved Insulin Therapies for Diabetes. Ph.D. Thesis, Massachusetts Institute of Technology. Dept. of Chemical Engineering, Berkeley, CA, USA, 1985.

41. Hernández-Ordoñez, M.; Campos-Delgado, D. An extension to the compartmental model of type 1 diabetic patients to reproduce exercise periods with glycogen depletion and replenishment. J. Biomech. 2008, 41, 744-752. [CrossRef]

42. Berger, M.; Rodbard, D. Computer simulation of plasma insulin and glucose dynamics after subcutaneous insulin injection. Diabetes Care 1989, 12, 725-736. [CrossRef] [PubMed]

43. Lehmann, E.; Deutsch, T. A physiological model of glucose-insulin interaction in type 1 diabetes mellitus. J. Biomed. Eng. 1992, 14, 235-242. [CrossRef]

44. Wilinska, M.E.; Chassin, L.J.; Schaller, H.C.; Schaupp, L.; Pieber, T.R.; Hovorka, R. Insulin kinetics in type-1 diabetes: Continuous and bolus delivery of rapid acting insulin. IEEE Trans. Biomed. Eng. 2005, 52, 3-12. [CrossRef] [PubMed]

45. Jahoda, P. MPAndroidChart. 2016. Available online: https://github.com/PhilJay/MPAndroidChart (accessed on 15 November 2018).

(C) 2020 by the authors. Licensee MDPI, Basel, Switzerland. This article is an open access article distributed under the terms and conditions of the Creative Commons Attribution (CC BY) license (http://creativecommons.org/licenses/by/4.0/). 